\title{
Transit Deserts: The Gap between Demand and Supply
}

Junfeng Jiao, University of Texas at Austin

Maxwell Dillivan, Ball State University

\begin{abstract}
The term "transit desert" is a new concept that looks at the gap between level of transit service (supply) and needs of a particular population (demand). These populations are often referred to as "transit dependent," people that are too young, too old, or too poor or who are physically unable to drive. "Transit deserts" in this case are defined as areas that lack adequate public transit service given areas containing populations that are deemed transit-dependent. This study aims to analyze and establish a clear method for calculating and quantifying gaps between transit demand and supply using Geographic Information Systems (GIS). The study looks at four major U.S. cities: Charlotte, North Carolina; Chicago, Illinois; Cincinnati, Ohio; and Portland, Oregon. Transit deserts often occur in neighborhoods surrounding historic downtowns; however, exceptions occur in very isolated rural areas.
\end{abstract}

\section{Introduction}

The concept of "transit deserts" introduced in this study is similar to the increasingly popular concept of "food deserts" (Clark et al. 2002; Whelan et al. 2002; Wrigley 1993; Wrigley et al. 2002; Jiao et al. 2012). Enormous attention has been paid to improving food systems and food environments through planning efforts to achieve equitable access to high-quality, affordable food for everyone. Food desert analyses identify geographic locations where concentrations of people who lack access to healthy food exist in the urban landscape. Similar analysis can be applied to mass transportation systems as well. While access to healthy, affordable foods 
has been compromised due to suburban sprawl (Morland et al. 2002; Jiao et al. 2012), choice of modes of transportation have as well. Taking the concept of food deserts and applying it to public transportation enables spatial patterns to emerge regarding service provision and service need. Locations of vulnerable populations can be determined and analyzed. There has been almost no research done using this approach to evaluating transit systems based on gaps between demand and supply in a spatial context.

Transit deserts are generally defined as areas containing a large constituent of transit-dependent populations with limited automobile access where the level of mass transit service (supply) does not adequately service these populations (demand). Areas of high concentrations of people who rely on public transportation for daily activities are in the greatest need of the provision of transit services. Transit-dependent populations typically are those who are too young, too old, or too poor or who are physically handicapped and unable to drive (Grengs 2001). "Transit deserts" in this case are defined as areas that lack adequate public transit service given areas containing populations that are deemed "transit dependent." Various indicators such as age, income, and access to a private vehicle are used to determine dependency. Since transit-dependent populations comprise individuals who rely on transit systems for access and mobility, this population will benefit most from investments made in high-quality, reliable, and frequent transit service (CATA 2011). Currently, a significant portion of mass transit riders are completely dependent upon the various forms of urban mass transportation in a time when dependency is likely to increase with car-ownership rates slowing and worldwide oil reserves dwindling.

\section{Literature Review}

Public transportation is vital to the health of cities. The United States Supreme Court has recognized the right to travel as one of the fundamental rights guaranteed by the 14th Amendment to the U.S. Constitution and is a hallmark of full membership of American society (Sanchez and Brenman 2008). The early challenges to racial discrimination and segregation attacked discriminatory practices that limited access to mobility by minorities; today, this segregation of society still exists and is manifested through access of modes of transit. Sanchez and Brenman, in their 2008 book titled The Right to Transportation, identify several aspects of an equitable transportation system, such as ensuring opportunities for meaningful public involvement in the transportation planning process; distributing the benefits and burdens from transportation projects equally across all income levels and 
communities; providing high-quality services-with emphasis on access to economic opportunity and basic mobility - to all communities, emphasizing transitdependent populations; and equally prioritizing efforts to both revitalize poor and minority communities and expand transportation infrastructure. These facets of equitable transportation systems are critical in the foundation of a true pluralistic society that affords access and opportunities for all.

Urban planners are asked to promote equity and invoke fairness and justice for all populations (Deakin 1996). Often, this involves the endeavor of allocating public goods and services to those in the greatest need, usually low-income, disadvantaged populations. To better allocate public goods, equity and advocacy planning theory emerged in the 1960s and 1970s. This theory argues that planners should represent and advocate for the interests of poor and minority groups and aim to ameliorate social ills that plague urban populations (Paul Davidoff 1965; GarciaZamor 2009). Public transit service, as an important general public good, has drawn much attention during this movement (Krumholz 1982). Transit-dependent populations mark a notable group of people who are often excluded from access to employment opportunities, access to retail options, and overall participation in society. However, many public transportation agencies have neglected transitdependent populations (Garrett and Taylor 1999). Garrett and Taylor (1999) argue that superior political power from suburban communities has created tension among transit planners in regard to meeting demands for low-income, inner-city residents who need transit and meeting the demands for more dispersed, wealthier suburban communities. Today, transit riders, on average, are much poorer than the general population with a disproportionate number of older adult and disabled riders. However, transit subsidies have been concentrated primarily on serving lower-density, higher income areas and improving transit access only for suburban residents, thus failing to respond to the needs of residents who rely on the service.

\section{Objective}

This study aims to create a clear, concise method for calculating and quantifying the supply of transportation service that can be used for any location. Results from this study can be used, in part, to evaluate a transportation system as a whole. Ideally, this will lead to more efficient and effective allocation of resources, allowing the greatest output (i.e., ridership, social justice) given input (i.e., transportation subsidies/funding). 
This study aimed to analyze and quantify gaps between transit demand and supply using GIS in four major U.S. cities. The study created a graphic representation of portions of these cities where there is either an excess of service given the demand of the residents in that particular area or where the supply of transit service is not meeting the demands of the residents in the area. This will shed light on the bigger issue of appropriation of resources.

\section{Research Methods}

\section{Research Design}

A gap analysis for transit demand and supply was performed by comparing the level of transit dependency for an area and calculating the difference against the amount of transit supply in a city. The cities selected for this analysis were Charlotte, North Carolina; Chicago, Illinois; Cincinnati, Ohio; and Portland, Oregon. These four cities were chosen to include different-size cities in various geographic regions of the country and also were based on data availability.

\section{Data}

Demographic data of the four cities were collected from the 2010 U.S. Census. The data were joined in GIS to census block groups to map transit dependency by block group. Municipal boundaries, transit stops, transit routes, bike lanes, and sidewalks were provided by the respective municipal GIS departments and transit agencies in each city. Data for transit frequency, trips, and stops was obtained from Google's General Transit Feed Specifications (GTFS), a common format for public transportation schedules and associated geographic information developed by Google and TriMet (Portland, OR) to publish data in an interoperable way (Google 2012).

\section{Measurement}

Transit-dependent populations for each city were calculated at the census block group level based a formula developed by the U.S. Department of Transportation (Steiss 2006) ${ }^{1}$ and slightly modified in a recent transportation study performed by the Capital Area Transit Authority in Lansing, Michigan (CATA 2011). This formula acknowledges that while identifying transit-dependent populations is an important tool for determining where new transit service should be provided or how existing systems can be modified to better service the population in need, calculating a single value that represents those who are transit-dependent can be difficult. While transit dependents are usually classified as those who are too young, too old, or too poor or who are physically unable to drive, Census data on these topics 
do not account for the fact that these groups often overlap. Simply counting each criterion and adding them together may double or even triple count certain individuals. The formula used to calculate transit dependents is as follows:

Household drivers $=$

(population age 16 and over) - (persons living in group quarters)

Transit-dependent household population $=$ (household drivers) - (vehicles available)

Transit-dependent population $=$ (transit-dependent household population) + (population ages 12-15) + (non-institutionalized population living in group quarters) ${ }^{2}$

The above calculation was performed for each block group. For block groups with more vehicles than household drivers, the transit-dependent household population was considered to be zero. The reasoning for this is that no block group should have a negative number of people who are transit-dependent.

This calculation changes the focus from why individuals may not drive (age, income, mobility) to identifying where there are limited vehicles available for individuals to use. This means areas with large disparities between auto drivers and autos available are more likely to be transit-dependent than areas that have nearly a one-to-one ratio of cars to people. Once this calculation was performed, the total number of the transit-dependent population was divided by acres for each block group and a z-score was calculated.

Transit service (supply) was determined by four criteria:

1. number of bus and rail stops in each block group

2. frequency of service for each bus and rail stop per day (weekday service) in each block group

3. number of routes in each block group

4. length of bike routes and sidewalks (miles) in each block group

Each criterion was divided by acres to get a density value and then a z-score value was calculated to standardize them. Finally, the values for each criterion were aggregated to determine the level of supply. In the end, demand and supply are subtracted and a final numerical value was calculated for each census block group to determine an excess or lack of supply (Hulchanski 2010). 


\section{Analysis}

Using various spatial analysis functions available in ArcGIS, transit demand and supply were calculated. Transit demand per block group was calculated using the formula presented previously. The database was imported into ArcGIS and joined to the block group shapefile by the common block group ID field. Transit supply per block group was calculated in ArcGIS. The four criteria were given z-score values, summed, and then averaged in a final supply total sum. This value was subtracted from the demand z-score values for each census block group to get the transit service discrepancy. The final maps illustrate differences between demand and supply.

\section{Results}

Each city's transit supply and demand were mapped using GIS. Chicago had the largest transit system of the four cities (Table 1). The Chicago Transit Authority (CTA) manages more than 3.1 million trips system-wide, with 148 individual routes ( 140 bus and 8 heavy rail) and 12,000+ bus and rail stops. Chicago's massive transit system is spread across its large municipal boundary of 234 square miles, which includes a total population of nearly 2.7 million residents. CTA boasts an average weekday ridership figure of approximately 1.7 million riders. This is split modally by 713,500 riders on Chicago's heavy rail system, the "L," as well as 998,600 riders on the city's buses. Additionally, 304,700 average weekday riders are included on Chicago's commuter rail, Metra. The city also contains nearly 650 miles of bike lanes and 4,700 miles of sidewalks.

Portland, while much smaller geographically (145 square miles), has a comparably large system, with almost 3 million trips and 7,000 bus and rail stops. Portland's TriCounty Metropolitan Transportation District of Oregon (TriMet) operates a mixture of light rail and bus services like Chicago. Given Portland's relatively small population and area, the city boasts an incredibly extensive transit network. Charlotte has the largest urban area but the smallest transit system (in terms of the number of trips per day and the number of total transit stops). Cincinnati has the second smallest urban area and the second smallest transit system, which provides bus service only.

Table 2 shows the top five block groups in each of the four cities with the highest level of demand. The values are reflected in terms of z-scores and are expressed by number of standard deviations from the mean. Most block groups with high demand are often located in low-income inner-city neighborhoods. Chicago and Portland experience the highest levels of demand due to lower rates of car owner- 
Table 1. Overview of Transit Systems in Four Cities

\begin{tabular}{|c|c|c|c|c|}
\hline Measurements & $\begin{array}{c}\text { Charlotte, NC } \\
\text { Charlotte Area } \\
\text { Transit System } \\
\text { (CATS) }\end{array}$ & $\begin{array}{l}\text { Chicago, IL } \\
\text { Chicago } \\
\text { Transit } \\
\text { Authority } \\
\text { (CTA) }\end{array}$ & $\begin{array}{c}\text { Cincinnati, OH } \\
\text { Southwest Ohio } \\
\text { Transit } \\
\text { Authority } \\
\text { (SORTA) }\end{array}$ & $\begin{array}{l}\text { Portland, OR } \\
\text { Tri-County } \\
\text { Metropolitan } \\
\text { Transportation } \\
\text { (TriMet) }\end{array}$ \\
\hline Population & 731,424 & $2,695,598$ & 296,943 & 583,776 \\
\hline Area (sq. mi.) & 297.7 & 234.0 & 79.6 & 145.4 \\
\hline Density (pop/sq. mi.) & 2,457 & 11,520 & 3,730 & 4,015 \\
\hline Routes & $\begin{array}{l}70 \text { (bus: } 69, \\
\text { light rail: } 1 \text { ) }\end{array}$ & $\begin{array}{l}148 \text { (bus: } \\
\text { 140, heavy } \\
\text { rail: } 8 \text { ) }\end{array}$ & 49 (all bus) & $\begin{array}{l}85 \text { (bus: } 79 \text {, light rail: } \\
\text { 4, commuter rail: } 1, \\
\text { streetcar: } 1 \text { ) }\end{array}$ \\
\hline Stops & 3,634 & 12,169 & 4,740 & 7,019 \\
\hline Ridership (avg. wkdy) & $\begin{array}{l}83,700 \text { (bus: } \\
69,100 \text {, light } \\
\text { rail: } 14,600)\end{array}$ & $\begin{array}{l}\text { 1,712,100 } \\
\text { (bus: } \\
998,600, \\
\text { rail: } \\
713,500 \text { ) }\end{array}$ & 53,100 & $\begin{array}{c}323,300 \text { (bus: } 191,600, \\
\text { light rail: } 126,500, \\
\text { commuter rail: } 1,600, \\
\text { other: } 3,600 \text { ) }\end{array}$ \\
\hline Trips & 0.16 million & 3.1 million & 0.35 million & 3 million \\
\hline Length, bike lanes (mi) & 65.9 & 623.9 & 58.8 & 648.7 \\
\hline Length, sidewalks (mi) & $3,212.7$ & $4,772.6$ & N/A & $4,759.5$ \\
\hline Demand (per acre) & $\begin{array}{l}\mu=0.97 \\
\sigma=1.27\end{array}$ & $\begin{array}{c}\mu=9.37 \\
\sigma=16.03\end{array}$ & $\begin{array}{l}\mu=1.81 \\
\sigma=2.35\end{array}$ & $\begin{array}{l}\mu=3.10 \\
\sigma=5.02\end{array}$ \\
\hline Supply (per acre) & $\begin{array}{l}\mu=0.33 \\
\sigma=0.87\end{array}$ & $\begin{array}{l}\mu=4.16 \\
\sigma=8.07\end{array}$ & $\begin{array}{l}\mu=1.16 \\
\sigma=2.39\end{array}$ & $\begin{array}{l}\mu=7.23 \\
\sigma=9.79\end{array}$ \\
\hline Gap & $\begin{array}{c}\mu=-0.64 \\
\sigma=1.27\end{array}$ & $\begin{array}{l}\mu=-5.21 \\
\sigma=13.94\end{array}$ & $\begin{aligned} \mu & =-0.65 \\
\sigma & =-2.43\end{aligned}$ & $\begin{array}{l}\mu=4.13 \\
\sigma=8.77\end{array}$ \\
\hline
\end{tabular}

ship, as the density of these two cities makes it economically and physically more difficult to own and operate an automobile within the city. Most block groups with the highest demand in each city are not adequately met with supply. These are areas that require the greatest attention and resources for planners. The method used in this study evaluates each geography and provides transportation planners with a useful evaluation tool that compares a metropolitan area's supply and demand level among other geographic areas of the city. For instance, Chicago's mean level of supply is much higher than the other cities compared. It would be unfair to use this level of service to evaluate other metropolitan areas (i.e., Charlotte and Cincinnati). Maps of demand, supply, and gaps for each city are shown in Figures 1 through 4 . In the gap maps, the darker the shading, the greater the gap. 


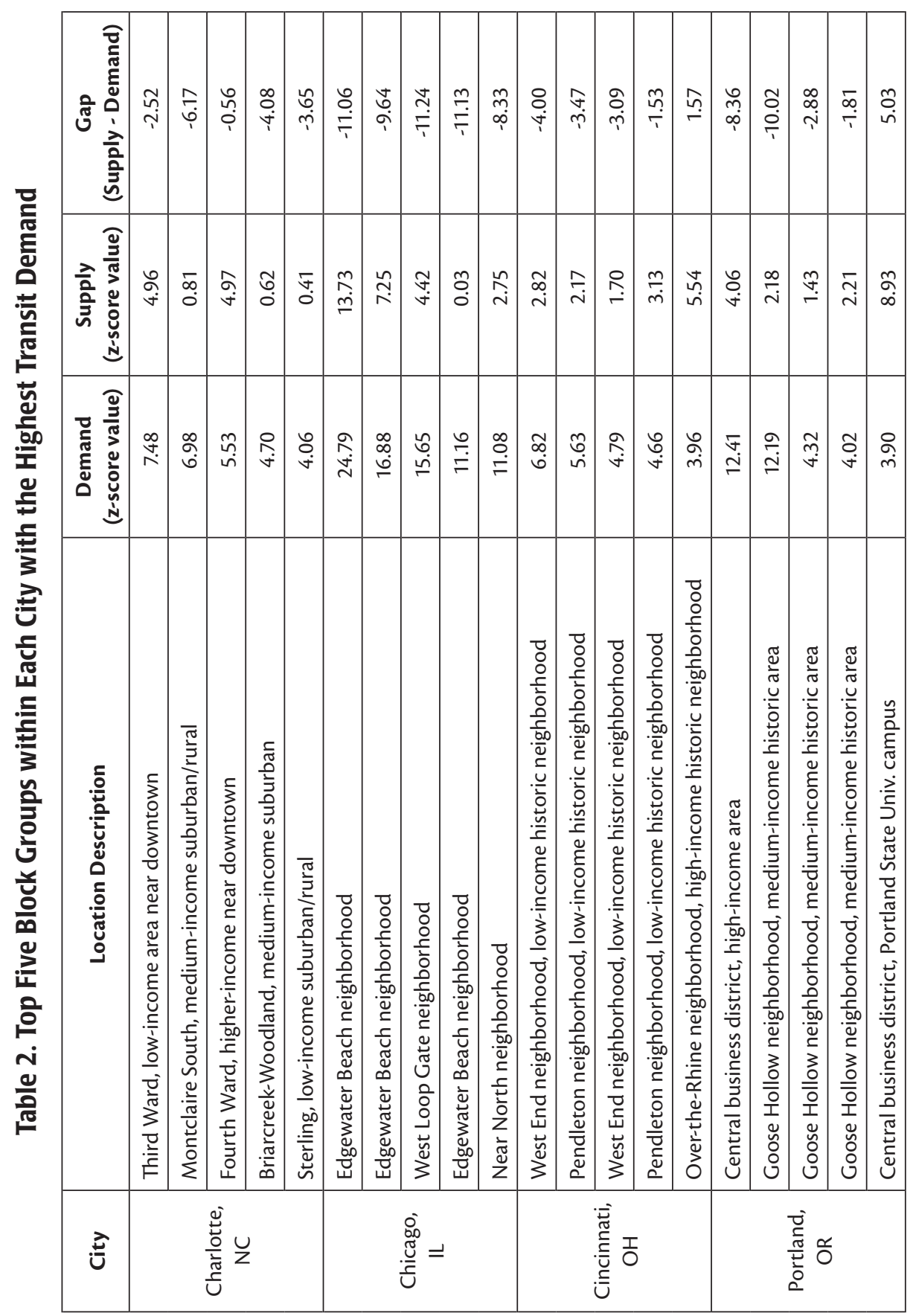




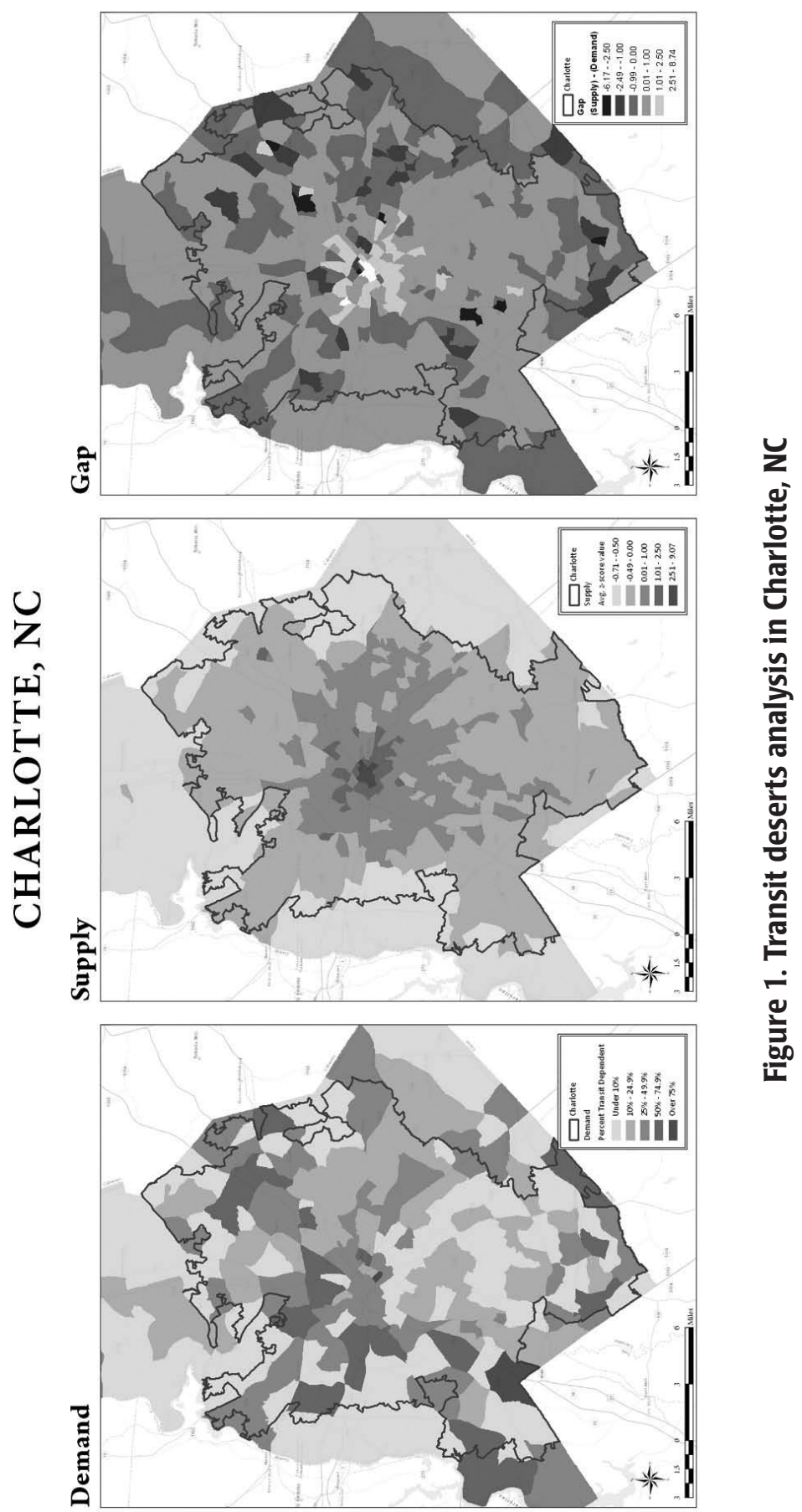


Journal of Public Transportation, Vol. 16, No. 3, 2013






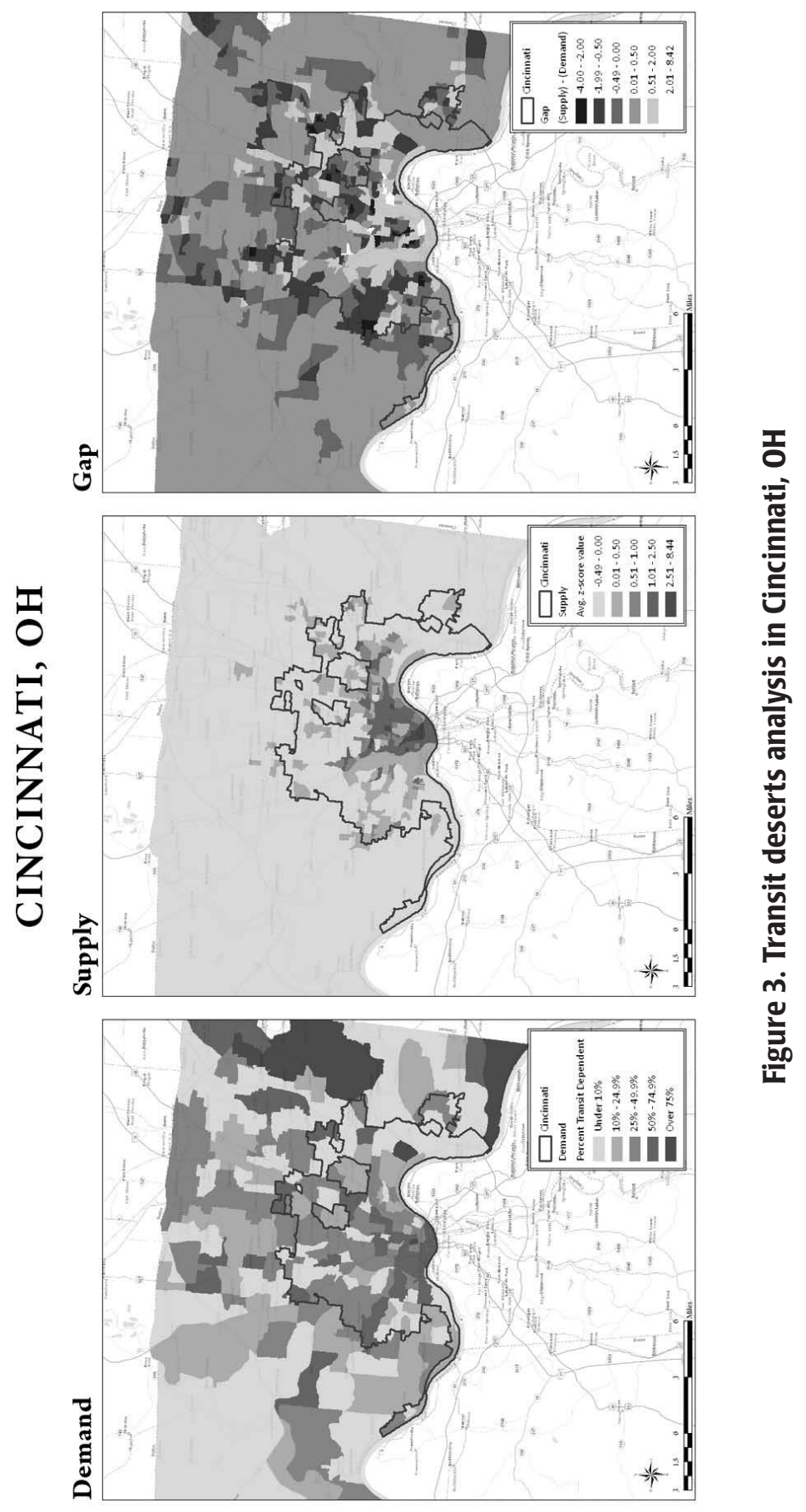


Journal of Public Transportation, Vol. 16, No. 3, 2013






\section{Discussion}

Transit deserts were discovered in areas in all four cities. Spatially, transit deserts were typically concentrated close to the downtown where cities most often have their major transit centers operating on a "hub and spoke" type of system. Supply for each city was relatively predictable; highest concentrations occurred in or near the central business district and service supply decreased as distance from the center increased. The gap analysis yielded some interesting results for each city.

In the case of Charlotte, its 3,600+ stops and 70 routes are concentrated mostly in the city center. Supply follows a logical spatial pattern across the city. However, transit-dependent populations (demand) are most dense on the fringes of the city and the inner-city neighborhoods to the north and west of the downtown. The areas with the highest transit dependency are skewed by the Charlotte Douglas International Airport and a very high-intensity industrial area on the city's southwest side.

Charlotte's highest concentrations of transit-dependent populations are fairly well-served. There are a few census block groups with greater demand than supply. Some neighborhoods just north of the downtown do not have demand that is met, however. As can be seen in Figure 1, many of Charlotte's most transit-dependent areas exist in suburban or rural portions of the city. This may be caused by several areas lacking adequate sidewalk and bike facilities. Since most of Charlotte's population and area growth occurred since the 1950s, the vast majority of the city is automobile-oriented. This has left much of the area surrounding the central business district to be developed at a low density.

Chicago presents an interesting scenario. Historically, the city has developed around commuter rail lines, which has led to the establishment of some of the city's most prominent neighborhoods. Today, the level of transit dependency appears very high, particularly in more affluent neighborhoods. The city exhibits, by far, the highest levels of transit dependency, with its highest block group having a score of 24.79 (the city with the next highest was Portland with only half that value). Thus, we see relatively few transit deserts in the city of Chicago, which is well-served by high levels of transportation services (Figure 2). There are instances of transit deserts, however, particularly in the farthest north neighborhoods of the city within the Edgewater neighborhood as well as a few block groups just outside of the city's "Loop." 
Cincinnati also follows a similar pattern of supply. Transit routes come in to the city center, located along the Ohio River. Spatially, transit deserts are much more random in Cincinnati, occurring in older neighborhoods north and west of downtown, but several more exist in suburban and exurban developments. The highest concentrations are within its historic neighborhoods adjacent to its central business district. The West End and Pendleton neighborhoods are low-income historic neighborhoods, which have the highest rates of dependency coupled with very low rates of supply - the highest block group has a score of 3.13. Interestingly, the Over-the-Rhine neighborhood, a quickly gentrifying neighborhood also located just north of downtown Cincinnati, is considered to be in this category due to its high transit demand, but it has a much higher supply rating of 5.54, thus leaving the area sufficiently served by transit (Figure 3).

By area, Portland has the greatest level of transit service per area and population compared to the other three cities, by far. In fact, the city has gained notoriety for its exceptional transit service. It is similar to Chicago from the standpoint that its transit demand appears high largely because many of the city's residents choose to not own a car in favor of taking transit. Three of Portland's five block groups with the highest demand for transit are fairly well-served, and all are located either in the central business district or adjacent to it. Several of the neighborhoods west of the Willamette River are extremely well served, as can be seen in the gap analysis of the city in Figure 4.

\section{Conclusions and Limitations}

This research is important for two primary reasons. First, the study aims to illustrate and turn the focus to neighborhoods in major cities whose transit needs are not being meet. This is useful in terms of public transit planning where new routes and stops should be located as well as how much service certain areas should receive. Transit-dependent populations mark an increasingly important demographic of people who often are marginalized from society and excluded from access to employment, retail, and overall participation in society. Roseland (2005) opined that "social equity demands that we balance the needs of the biosphere with the needs of the vast majority of the human population, the world's poor." From this perspective, social equity is understood as an effort to address the injuries and injustices meted out to those excluded from a protected class. These injuries and injustices manifest themselves in a variety of ways, resulting in traumatic experiences for the physical landscape as well as the human encounter where the fundamental rights of citizens are compromised (Garcia-Zamor 2009). 
Second, this study approaches a transportation problem with a new paradigm and establishes a method for quantifying and calculating locations with inadequate transit service given a population's needs. Relatively no literature was found on this topic, which makes this study an important stepping stone to refine and evaluate public transportation service. In an era with dwindling budgets for public agencies, efficiency and effectiveness are paramount. Public dollars need to be spent as sensibly as possible. This study allows more sensible solutions to be determined and adds to the discourse of transportation planning methods.

There are few limitations in this research. First, it should be recognized that any method to evaluate transit-dependent populations is a difficult one. The method chosen for this study was one that was most pragmatic and sensible. Because of this, the study cannot correlate exactly why high levels of transit dependency occur in certain areas. For example, the analysis of Chicago showed a high transit dependency in the Edgewater Beach neighborhood on the far north side of the city. However, the neighborhood is known to have a satisfactory level of transit service. The reason for this lies in the study's low geographic scale. One of goals of this study was to obtain a high level of data for the smallest unit of geography possible, thus gaining the more precise knowledge of a particular area. Coupled with Chicago's high population density, block group geographies in this portion of the city are comparatively very small. While bus or train stops might only be a block away, this is not reflected in the data. Thus, certain areas that, in reality, are served well by transit, are shown as bereft of service.

Last, this study also met data limitations when trying to calculate certain criteria for transit supply. Census data for vehicles available is not publicly available by block group geography and had to be adjusted from the census tract level.

\section{Endnotes}

1 U.S. Department of Transportation, Federal Highway Administration (FTA), Bureau of Transportation Statistics. FTA published the Census Transportation Planning Package 2000 Status Report in cooperation with the Transportation Research Board Census Subcommittee.

${ }^{2}$ Non-institutionalized populations living in group quarters include persons living in dormitories and fraternity, and sorority houses. 


\section{References}

American Public Transportation Association (APTA). 2012. Public Transportation Ridership Report, Fourth Quarter 2011. Washington, DC.

Capital Area Transit Authority (CATA). 2011. Michigan/Grand River Avenue Transportation Study. Lansing, MI.

Clark, G., H. Eyre, and C. Guy. 2002. Deriving indicators of access to food retail provision in British cities: Studies of Cardiff, Leeds, and Bradford. Urban Studies 39(11): 2041-2060.

Davidoff, P. 1965. Advocacy and pluralism in planning. Journal of the American Planning Association 13(4): 331-338.

Deakin, E. 1996. Social Equity in Planning. Berkeley Planning Journal 13: 1-5.

Garcia-Zamor, J. 2009. Social equity in urban development. The Leipzig experience. International Review of Public Administration 14(2): 1-11.

Garrett, M., and B. Taylor. 1999. Reconsidering social equity in public transit. Berkeley Planning Journal 13: 6-27.

Google. 2012. Google Transit Feed Specification (GTFS) Overview. Google Developers.

Grengs, J. 2001. Does public transit counteract the segregation of carless households? Transportation Research Record 1753: 3-10.

Hulchanski, D. 2010. The Three Cities Within Toronto: Income Polarization Among Toronto's Neighborhoods, 1970-2005. University of Toronto, Toronto, Canada.

Jiao, J., A. V. Moudon, and A. Drewnowski. 2011. Grocery shopping: How individuals and built environments influence travel mode choice. Transportation Research Record 2230: 85-95.

Jiao, J., A. V. Moudon, J. Ulmer, P. Hurvitz, and A. Drewnowski. (forthcoming). How to identify food deserts: Measuring physical and economic access to supermarkets in King County, WA. American Journal of Public Health.

Krumholz, N. 1982. A retrospective view of equity planning. Journal of the American Planning Association 48(2): 163-174.

Krumholz, N., and P. Clavel. 1994. Reinventing Cities: Equity Planners Tell Their Stories. Philadelphia: Temple University Press. 
Krumholz, N., and J. Forester. 1990. Making Equity Planning Work: Leadership in the Public Sector. Philadelphia: Temple University Press.

Morland, K., S. Wing, A. Diez Roux, and C. Poole. 2002. Neighborhood characteristics associated with the location of food stores and food service places. American Journal of Preventative Medicine 22(1): 23-29.

Roseland, M. 2005. Toward Sustainable Communities: Resources for Citizens and Their Governments. British Columbia: New Society Publishers.

Sanchez, T., and M. Brenman. 2008. The right to transportation. Planning Magazine 74(1): 44-47.

Steiss, T. A. 2006. Calculating/analyzing transit dependent populations using 2000 census data and GIS. Census Transportation Planning Package 2000 Status Report. U.S. Department of Transportation. Washington, DC.

Whelan, A. M., N. Wrigley, E. Cannings, and D. L. Warm. 2002. Life in a "food desert." Urban Studies 39(11): 2083-2100.

Wrigley, N. 1993. Retail concentration and the internationalization of British grocery retailing. Retail Change: Contemporary Issues. London: UCL Press.

Wrigley, N., D. Warm, B. Margetts, and A. Whelan, A. 2002. Assessing the impact of improved retail access in a "food desert": A preliminary report. Urban Studies 39(11): 2061-2082.

\section{About the Authors}

JUNFENG JIAO (jjiao@austin.utexas.edu) is an assistant professor in the School of Architecture at the University of Texas at Austin. He received his Ph.D. in urban planning and MSc in transportation engineering from the University of Washington. His research interests include public transportation, transportation modeling, GIS and GPS applications, and public health.

Maxwell Dillivan (mkdillivan@bsu.edu) recently graduated magna cum laude from Ball State University with a Master of Urban \& Regional Planning degree (emphasis in GIS and Comprehensive Planning). His research interests include public transportation, transportation planning, land use dynamics, and history of urban forms. 